\title{
ECONOMIC GROWTH AND SOCIAL CAPITAL IN ASIA
}

John F. Helliwell

Working Paper 5470

\author{
NATIONAL BUREAU OF ECONOMIC RESEARCH \\ 1050 Massachusetts Avenue \\ Cambridge, MA 02138 \\ February 1996
}

Revised version of paper delivered at the Industry Canada Conference on the Growing Importance of the Asia-Pacific Region to the World Economy, Vancouver, December 1-2, 1995. I am grateful for helpful comments of conference participants, and especially Francis Colaço. The paper was written while visiting the NBER and the Harvard Center for International Affairs, and I am grateful for hospitality and helpful discussions, and for the financial support of the Hongkong Bank Fulbright Fellowship and the Social Sciences and Humanities Research Council of Canada. This paper is part of NBER's research programs in Economic Fluctuations and Growth, and International Trade and Investment. Any opinions expressed are those of the author and not those of the National Bureau of Economic Research.

(C) 1996 by John F. Helliwell. All rights reserved. Short sections of text, not to exceed two paragraphs, may be quoted without explicit permission provided that full credit, including ( $)$ notice, is given to the source. 


\title{
ECONOMIC GROWTH AND SOCIAL
}

CAPITAL IN ASIA

\begin{abstract}
The paper reviews the growth performance of different groups of Asian economies, confirms the role of openness as a key factor explaining the growth differences among the Asian economies, and undertakes a preliminary investigation of the role of social capital and institutions. The role of openness in explaining growth differences among the Asian economies appears to be if anything greater than has been established in global samples. Various measures of social capital and institutional quality were not found to add explanatory power, perhaps because of the shortage of comparable data for the Asian economies. It is conjectured that the prospects are good for the technological catchup that has taken place in South-East Asia to be repeated elsewhere in Asia, and especially South Asia, partly in response to recent increases in openness. The role of social capital and institutions in facilitating this catchup remains to be established.
\end{abstract}

John F. Helliwell Department of Economics University of British Columbia Vancouver, BC, V6T 1Z1 CANADA and NBER 
This paper will consider some of the special features and implications of Asian economic growth experiences. I shall start by updating and extending the comparative analysis of Asian economic growth in Helliwell (1995), and then introduce some new elements into the discussion, most especially trying to see if analysis of social capital and institutions of the sort emphasized by Putnam for the regions of Italy (Putnam 1993, Helliwell and Putnam 1995) and for the United States (Putnam 1995, 1996) can help to explain growth differences among Asian economies or between South-East Asia and the rest of the world.

\section{Asian Growth in a Global Perspective}

As shown in Figure 1, economic growth in China and in Asia as a whole has been much faster, on average, than in the rest of the developing world, and developing countries as a group have grown faster than the industrial countries. For example, over the 1987-94 period, real GDP growth in the developing countries averaged $2.75 \%$ per annum more than in the industrial countries, and this growth difference is projected to continue at 3\% through 1995 and 1996 . Over this same period, population growth has averaged about $0.5 \%$ in the more developed countries and $2 \%$ in the less developed countries. Thus per capita as well as aggregate growth rates have been faster in the developing countries than in the industrial countries, hence narrowing the proportionate income gap between rich and poor.

Although Figure 1 shows fast economic growth in Asia, it is important to remember that per capita income growth in Asia starts from a low base. As Figure 2 shows, although more than half of the world's population is in Asia, it produces less than one-quarter of the world's GDP, so that GDP per capita in Asia is still less than one-half as high as in the world as a whole. However, this is much higher than a decade previously, thanks to the high Asian growth rates in the intervening period. Per capita incomes in the OECD are still three times the world average, or eight times as high as in Asia. Incomes in the countries in transition (marked 'trans' in the figure, and comprising the countries of the former USSR and Eastern Europe) were more than the world average at the beginning of the decade, but are now less in the wake of several years of shrinking real GDP. Per capita incomes in Latin America are just equal to the global averages, while those in Africa have fallen behind those in Asia. Even these continental averages hide much variety, both 
in levels and rates of growth of per capita incomes'.

There has been ${ }^{2}$ in the past thirty-five years a fairly well documented convergence of both rates of growth and levels of per capita incomes among the industrial countries. Countries starting off with lower incomes have grown faster than the initially richer countries ${ }^{3}$. Some have interpreted this evidence ${ }^{4}$ as support for the idea that all countries have the same rates of efficiency growth, and hence that convergence is taking place through higher levels of investment in the poorer countries. However, numerous studies that use explicit production functions to define levels and rates of growth of technical progress show that most of the convergence among the industrial countries takes place through faster measured technical progress in the initially

\footnotetext{
${ }^{1}$ The data in Figures 1 and 2 are mainly drawn from the IMF World Outlook of May 1995. Data for individual Asian economies will be presented later. It should be noted that the shares of world GDP make use of purchasing power parities (PPPs) rather than market exchange rates to compare and combine real output in different countries. The United Nations continues to use market exchange rates for their international comparisons, which reduces the relative incomes of developing countries and regions, since real exchange rates are systematically lower in poorer countries, as documented in Summers and Heston (1991) and many other studies. The UN figures for 1994 show that suggest that only $12 \%$ of world GDP originates in Asia, while the IMF data show $23 \%$. The IMF data are much more meaningful, since the PPPs are designed to permit comparison of real incomes, while the measures used by the UN are systematically biased in a way that under-estimates the real GDP of poorer countries.
}

${ }^{2}$ This paragraph, the two following, and some of the subsequently listed points of view, are adapted from Helliwell (1995).

${ }^{3}$ Studies documenting the convergence among the industrial countries include Abramovitz (1979, 1990), Maddison (1982), Baumol (1986), Baumol and Wolff (1988), Dowrick and Nguyen (1989), Dowrick and Gemmell (1991), and Helliwell and Chung (1991a).

${ }^{4}$ Studies treating convergence, or convergence conditional on rates of investment in human and physical capital, as evidence supporting the idea of a common international production function with the same rate of technical progress in all countries include Barro (1991) and Mankiw, Romer and Weil (1992). Mankiw, Romer and Weil, however, conclude that the evidence requires that even though countries may all have the same rate of growth of productivity, the average levels of GDP per capita, for given levels of physical and human capital, may differ among countries because of differences in natural resources and other factors. 
poorer countries ${ }^{5}$. Attempts to find convergence among global samples of countries have found no unconditional convergence of income levels, whether or not allowance is made for the possibility that statistical problems may lead some estimates to find convergence of income levels where none may exist. However, when allowance is made for differences in education levels and investment rates, the global samples do show some evidence of conditional convergence.

Although this finding seems fairly robust to what specific variables are used to explain the factors other than convergence that influence growth rate differences, it is still sensitive to the statistical methods used, and is certainly not equally applicable throughout the developing world.

Of particular relevance to students of Asian growth is that the models that have so far been used to show convergence among the industrial and global samples often show no evidence of convergence among the Asian economies. When the global samples are split among continents, they show evidence of conditional convergence in the industrial countries and in Latin America, slight signs of convergence in Africa, and divergence in the sample of Asian economies ${ }^{6}$. The Asian experience may be disconcerting for enthusiasts of convergence, but it is of no more comfort for those who were advocating models of endogenous growth based on national

${ }^{5}$ Such tests are carried out and reported in Dowrick and Gemmell (1991), Helliwell and Chung (1991a), Coe and Helpman (1993), and Helliwell (1994c). These studies typically follow the example of Solow $(1956,1957)$ by inverting a neoclassical production function to obtain a measure of total factor productivity now often referred to as 'Solow residuals'. An alternative procedure is followed by Boskin and Lau (1992), who use the notion of a meta production function equally applicable to all countries, with differences among countries and factors in the efficiency of factor use. They also find convergence in rates of technical progress among the industrial countries, but in their setup it comes from their estimates of declining returns to capital.

${ }^{6}$ These results are reported in Helliwell and Chung (1995). Subsequent more detailed study of the Asian sample, reported in Helliwell (1994a), shows apparent evidence of strong influence from investment and several measures of openness, with a possible negative effect from democracy, but with still no signs of conditional convergence. In still more recent work, Fukuda and Toya (1994) argue that export-led growth is the secret of the growth successes in Asia, and report some evidence of conditional convergence once differences in export intensity are accounted for. 
spillovers from domestic accumulation of human or physical capital ${ }^{\top}$, since the fastest growing countries in East Asia included the very smallest, and hence provided no signs of returns to scale. More recent theoretical and empirical studies are starting to realize that convergence is taking place, where it is happening, mainly through international transfers of knowledge, and that these transfers can best be analyzed using theories of the production and distribution of knowledge that lie at the heart of the endogenous growth literature ${ }^{8}$.

A principal aim of this paper is to extend the analysis in Helliwell (1995) of the possible reasons for the different growth experiences within Asia, and the growth differences between Asia and the rest of the world. Naturally, there has been a substantial literature springing up to explain why some Asian economies have grown faster than the rest, and to search for lessons that may be transferable to other countries. The literature contains several types of argument:

- Growth experiences vary a great deal from decade to decade for each country, so that differences among countries, or groups of countries, are likely to be ephemeral, and hence to depend more on 'good luck' than on 'good policy'.

- Once appropriate allowances have been made for the large increases in labour force participation rates and for high investment levels, the rates of total factor productivity increase in the four tigers are not unusually high, especially when compared to those in the

${ }^{7}$ See, for example, Lucas (1988, 1990), and Romer (1986). Evidence showing no economies of scale among developing countries is reported in Helliwell and Chung (1995), and their small aggregate size in industrial countries is reported by Backus, Kehoe and Kehoe ((1991) and Helliwell and Chung (1991b).

${ }^{8}$ See, for example, Grossman and Helpman (1991), Coe and Helpman (1993), Romer (1994) and Lucas (1993). For an empirical example applied to the Asian growth experience, see Ruffin (1993).

${ }^{9}$ For this view, see Easterly, Kremer, Pritchett and Summers (1993), and Easterly (1994) 
industrial countries during their convergence in the $1960 \mathrm{~s}$ and $1970 \mathrm{~s}^{10}$.

- The eight 'high performing Asian economies' or HPAEs (the four tigers plus Japan, Malaysia, Thailand and Indonesia) do provide a remarkable mix of regionally concentrated and sustained high growth combined with low and declining levels of income inequality (World Bank 1993). The World Bank study attributes the growth to high rates of accumulation of physical and human capital, good macroeconomic management, declining population growth", and market-friendly government policies, perhaps aided in some countries by a number of 'market-leading' interventions to promote exports and growth ${ }^{12}$.

- Among those who think that there is indeed an East Asian growth miracle to explain, there is a variety of sometimes conflicting reasons offered to explain growth in one or more of the four tigers or eight HPAEs, including export promotion policies, industrial strategies, directed lending in financial markets, domestic competition policies, free trade and capital movements, economic freedoms, cultural factors, and a stable political and social order.

In a previous paper (Helliwell 1995), I noted the need to explain why some of the Asian economies have taken off into sustained growth while others have not yet done so. In this paper I propose to explore that question in more institutional detail, paying particular attention to issues of cultural differences and social organization that have received much attention but little

${ }^{10}$ This view is developed for Hong Kong and Singapore in Young (1992), and for all four tigers in Young (1995), where average annual growth of total factor productivity from 1966 to 1990 is estimated to be $2.3 \%$ for Hong Kong (to 1991 ), $-0.3 \%$ for Singapore, $1.6 \%$ for South Korea and $1.9 \%$ for Taiwan.

"For evidence that fertility declines precede rather than lag higher growth rates, see Brander (1992, 809-10).

${ }^{12}$ Rodrik (1994) is critical of the World Bank Report for not having or presenting adequate empirical evidence to support their judgements about the types of interventionist policies under review. Rodrik himself gives more causal weight than does the Bank report to the equality of income distribution that is characteristic of the HPAEs, and which the World Bank reports as an attractive feature of the HPAE growth record. 
quantitative analysis, principally because of the difficulties in measuring how and explaining why differences in cultures and social institutions affect international differences in growth rates and the levels of well-being. But first I shall summarize the major empirical results of the previous paper, and present more recent data on the past and projected growth rates in the larger Asian economies.

\section{Comparative Growth in the Asian Economies}

The empirical results in this paper continue where those in the previous paper left off, with differences in openness being used as a likely starting point in explaining the growth differences among the Asian economies, and in reconciling the differences between the Asian growth experiences and those elsewhere in the world ${ }^{13}$. Figure 3 repeats the primary result from my previous research (Helliwell 1995) showing that dividing the Asian sample into three groups with differing degrees of openness at the beginning of the 1980s explains more than half of the variation in 1980 s per capita growth rates among the Asian economies. The equation is as follows:

Per capita GDP90/Per capita GDP80 = $\begin{array}{ccc} & \\ & 4.78 \text { tariff } & -.0065 \text { GDP80 } \\ \text { Rsq }=.555 & \text { SEE }=.185 \quad \mathrm{~N}=16\end{array}$

where the tariff rate is the average proportionate import tariff in 1980 and GDP80 for each country is measured as a percentage of real per capita income in the United States ${ }^{14}$.

The lines in Figure 3 show the conditional forecasts for 1980s growth for countries in each of the three tariff categories. The low tariff countries, with tariffs averaging $1.2 \%$ in 1980 , are Taiwan, Singapore, Hong Kong, and Japan. The medium tariff countries, with 1980 import tariffs

${ }^{13}$ Supporting references include Ben-David (1993, 1994), Dollar (1992), Edwards (1993), Harrison and Revenga (1995), Helliwell (1994c) Lee (1993), and Sachs and Warner (1995).

${ }^{14}$ This is the variable $Y$ from version 5.6 of the Summers-Heston ICP data. 
averaging $7.7 \%$, are Indonesia, South Korea and China. The high tariff countries, with rates averaging 15.6\% in 1980, were Bangladesh, India, Pakistan, Nepal, Sri Lanka, the Philippines, Thailand, Malaysia and Myanmar ${ }^{15}$. The lines slope down from left to right, reflecting the conditional convergence effect implied by the estimated negative coefficient on per capita income at the beginning of the decade. The coefficient on the tariff variable suggests that a drop in tariff rates averaging one percentage point was associated with a per capita growth difference cumulating to $4.4 \%$ over the decade. This is undoubtedly a substantial over-estimate of the consequences of tariff reductions viewed as an independent instrument of policy. It is more appropriate to view the size of the estimated coefficient on the tariff rate as the combined effect of a whole range of policies and events that encouraged the inflow and implementation of productive ideas from abroad. In general, the developing countries of Asia and elsewhere design and implement inward or outward-looking strategies in packages, with varying mixes of tariffs, nontariff barriers, exchange controls, foreign investment controls, taxes, and regulations governing the flows of trainees and workers. Estimates based on the more comprehensive openness measure developed by Sachs and Warner (1995) also show large growth effects of openness, in Asian and global samples alike. If we use the Sachs and Warner data for the extent of openness of the 16 Asian countries to repeat the 1980 s growth regression reported above, the results are as follows:

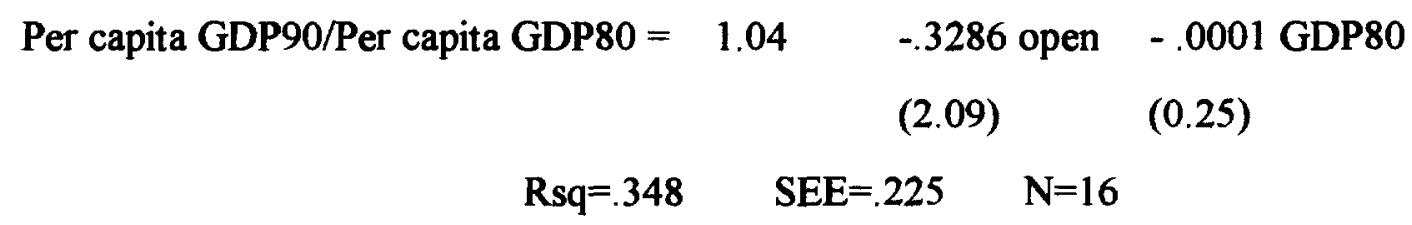

The openness variable takes the value 1.0 for countries classified as open throughout the 1980 s, 0.0 for those that were still ranked as closed in 1990, and an intermediate value for the one

${ }^{15}$ The tariff data were not available for Taiwan, China, and Myanmar, so these countries were assigned to the low, medium and high tariff categories on the basis of other measures of their openness to trade and investment. 
country becoming open partway through the decade ${ }^{16}$. The coefficient on the openness variable implies that a country that was open rather than closed for the 1980s grew by a cumulative $33 \%$ more over the decade, or $2.8 \%$ per year, very similar to the $2.5 \%$ per year estimated by Sachs and Warner for a global sample of 89 countries over the period 1970 through 1989. These estimates, if they are correct, tend to support the earlier estimates based on tariff classes, although they are somewhat smaller. The earlier estimate, of $4.4 \%$ cumulative growth for each percentage point drop in average tariffs, multiplied by the high-tariff-countries' average tariff rate of $15.6 \%$, would give a cumulative ten-year growth effect of $68 \%$. This is higher than the $38 \%$ based on the Sachs and Warner variable, but is based on moving to zero tariffs, while the Sachs and Warner open economies generally still have positive tariffs. If the high-tariff countries were to lower their average tariffs from $15.6 \%$ to the average of that for the low-tariff and medium tariff countries, $4.9 \%$, the implied increase in the accumulated ten-year growth would be $47 \%$, in the same range as the $38 \%$ implied by the Sachs and Warner variable. The results using the Sachs and Warner variable do not show significant convergence effects. Sachs and Warner would argue that this is because the sample of 16 still includes too many closed economies, which have many fewer opportunities for the technological transfer on which convergence is primarily based. When they divide their global sample into two subsets, one open and one closed, they find both conditional and unconditional convergence to be evident over the 1970-1989 period for the open economies, but not for the closed ones.

Turning to examine the past and current growth experiences of the individual Asian economies, as a prelude to consideration of some of the other possible determinants of faster growth, Figures 4a, 4b and 4c show the 1987 to 1998 past and projected growth rates of total GDP for three groups of Asian economies. Figure 4a shows Japan and the four tigers; Figure 4b

\footnotetext{
${ }^{16}$ The countries classified as open in 1980 are Taiwan, Hong Kong, Japan, Singapore, Malaysia, Thailand, Korea and Indonesia. Those classified as closed include China, India, Nepal, Pakistan, Bangladesh, and Sri Lanka. The Philippines is given the value 0.2, reflecting the Sachs and Warner reclassification from closed to open in $1988 .(0.2=(90-88) /(90-80))$
} 
China and other countries of South-East Asia, and Figure 4c several countries in South Asia ${ }^{17}$. Figure 4a shows the four tigers outperforming Japan for most of the 1990s, consistent with conditional convergence (since their average productivity levels are still below those in Japan), but driven also by the sharp drop in Japanese growth in the early 1990s. A broader range of growth experiences is shown in Figure 4c, with China on average having the fastest rate of growth, and Myanmar the lowest, with four ASEAN countries in the middle. Figure $4 \mathrm{c}$ shows the narrower and generally lower range of growth rates in South Asia, all of whose economies were in the high tariff group during the $1980 \mathrm{~s}$.

To help put the three groups of countries in a comparative context, Figure 5 shows average growth rates for China, the four tigers, four ASEAN economies, and the major economies of South Asia ${ }^{18}$. Although all three groups of countries (but not China, for which growth was slower in 1989 and 1990 in the aftermath of Tiannamen Square) had slower growth from 1991-94 than they did from 1987-90, the reduction was in all cases proportionately less than the reductions in the industrial countries, and in the world as a whole. For example, GDP growth for the world economy fell from $3.6 \% 1987-90$ to $2.4 \% 1991-94$, while that in the industrial countries was almost halved from $3.3 \%$ to $1.6 \%$. By contrast, average growth of the four tigers fell from $8.5 \% 1987-90$ to $6.8 \% 1991-94$, more in percentage points but much less as a fraction of the earlier growth. Growth reductions were even smaller for the four ASEAN countries, falling from $7.8 \%$ to $6.3 \%$. The same story applies to South Asia, where the $1987-90$ growth of $4.9 \%$ fell only to just under $4.7 \%$ in the $1991-94$ period. As a result, there has been a convergence of growth rates among the Asian economies, and this is expected to continue over the rest of the 1990s. Over the 1995-98 forecast horizon, the Project LINK projected growth rates average

17 The data for 1987 through 1993 are from the IMF World Outlook of May 1995, while the figures for 1994-98 are from the September 1995 World Outlook of Project LINK.

${ }^{18}$ The ASEAN countries include Indonesia, Malaysia, Philippines and Thailand. Singapore is excluded, since it has been included in the data for the four tigers, along with Hong Kong, Taiwan and Korea. The South Asian average is based on Bangladesh, India, Pakistan and Sri Lanka through 1994, and India and Pakistan for 1995-98. The averages are not weighted by country size. 
$6.4 \%$ for the four tigers, $7.7 \%$ for the four ASEAN countries, and 5.9\% for India and Pakistan.

All else equal, we might expect to see higher growth rates in South Asia than in ASEAN, and higher growth in ASEAN countries than among the four tigers, since existing income levels and comparative costs are much lower in South Asia than in ASEAN, and lower in ASEAN than among the tigers. Of course, all else is not equal, and the four tigers, which were not far from South Asian income levels in 1960, clearly grew faster over the next thirty years. If being poor were all it took to ensure higher growth rates, then Africa would be growing fastest of all, and there would remain the puzzle of how to explain why income differentials managed to arise in the first place. Much work on comparative growth has emphasized various sets of conditions and institutions ${ }^{19}$ that might tend to favour rapid growth. In the $1960 \mathrm{~s}$, there was more faith in internally-oriented import-substitution policies, as exemplified in many of the high-tariff countries in our Asian sample. In the 1970 s and 1980s, there came to be much greater hopes pinned on outward-oriented strategies, sometimes focussed on export-led growth, but more often on general increases in openness to world markets. This has been accelerated and accompanied by the several rounds of GATT agreements, and by the increasing insistence by donors that aid be made conditional on the establishment of more open trade and more stable macroeconomic conditions. The growth experiences of the Asian economies over the 1980s tend to support the view that the more open economies have indeed grown faster, but neither the channels nor the robustness of these results have been fully established.

The idea that growth can be faster in more open economies is supported by certain versions of endogenous growth theory, whereby technical progress is dependent to an important degree on the importation and use of technologies initially discovered and used elsewhere. There is uncertainty about whether these flows of productive ideas are linked to inward direct investment, exports, imports, high levels of domestic education, research and development at home or abroad, or some combination of these facilitating influences. A relatively new strand of empirical research has turned to consider whether there are measurable international differences in

${ }^{19}$ See, for example, Abramovitz (1979). 
the quality of domestic institutions, and in the structure of society more generally, that might facilitate either the more efficient use of ideas from elsewhere or the more productive use of domestic resources, or both. To give some taste of preliminary results in this vein, I shall discuss briefly some data and results on the effects of institutional quality, and then deal with measures of social capital more broadly conceived.

\section{How Important Are Institutions?}

There is a large and growing literature on the growth effects of democratic and other political institutions. I shall concentrate here on data collected and analyzed by Mauro (1995) which attempt to measure the quality of governmental institutions pertaining to foreign and domestic businesses. The data are from surveys of business opinions, chiefly among those who have operations in the countries in question. Mauro has collected data for 68 countries, thirteen of which are among the sample of Asian economies under consideration in this paper. Mauro develops an index of bureaucratic efficiency which is the sum of three separate measures of institutional quality: the efficiency of the judicial system, the absence of bureaucratic red tape, and the absence of corruption. It might have been more helpful if questions had been asked about the presence of good institutions as well as the absence of bad ones, but the data are what they are. The three component indices are fairly highly correlated in the global sample (.78 or .79 between each of the three measures), so the use of Mauro's combined index is not likely to be different from the use of one or more of the components. He prefers the combined index to help smooth possible errors of measurement that may be specific to a particular measure.

When the Mauro index of bureaucratic efficiency in 1981-3 is added to the 1980s crosssectional growth equation shown earlier, it has no effect, whether on its own or in combination with the tariff andlor initial income variables. However, there is a strong positive correlation $(r=86)$ between the level of real GDP per capita and the measures of institutional quality, with richer countries having higher degrees of bureaucratic efficiency. Figure 6 shows the crosssectional plot of Mauro's index and 1980 GDP per capita for the thirteen Asian countries for 
which the data are available. It would appear that countries acquire more efficient institutions as they get richer, but there is a somewhat puzzling lack of any influence from the institutional quality back to subsequent economic growth. Mauro finds similar results with his global sample, but does find an indirect role for his measure of bureaucratic efficiency in being associated with higher rates of investment in physical capital and education, both of which have been found to have positive effects on subsequent economic growth. However, if these indirect linkages were strong, we would expect to find them showing up in the reduced-form equation for growth in the Asian sample, since neither investment nor education variables are included in the equation, leaving the institutional variable free to take all the credit that might be due.

This result is reminiscent of my earlier attempts (Helliwell 1994b) to disentangle the twoway linkages between democracy and economic growth, with a strong effect found from the level of income to the presence of democratic institutions, but a weak negative or zero effect of democratic institutions back to subsequent economic growth. The latter result poses no great puzzle, as there are reasons to expect democracy to have mixed effects on subsequent economic growth. However, it is harder to think why the efficiency of governmental institutions could be bad for economic growth. Indeed, research measuring the quality of governmental institutions at the regional level in Italy (Putnam 1993) has led to subsequent estimates showing that regional growth is higher in regions with better governmental institutions, with the eventual size of the income gap restrained by conditional convergence effects ${ }^{20}$. Thus it remains somewhat surprising that differences in institutional quality, especially using measures aimed at the services supporting business activities, do not appear to explain any of the growth differences among the Asian economies in the 1980s. Measurement errors of course are likely to be important. However, the variables used are likely to be biased in a way that would make them positively rather than negatively correlated with subsequent growth, since they are based on the opinions of those planning future business decisions, and are hence likely to be influenced by other determinants of growth optimism or pessimism.

\footnotetext{
${ }^{20}$ Helliwell and Putnam (1995).
} 


\section{Social Capital and Cultural Differences}

It has often been suggested that part of the key to the development successes in Asia, and especially in South-East Asia, lies in a tighter and more robust set of social institutions than those found elsewhere in the modern world -e.g. "The glue that holds Asian societies and families together has not been weakened by modernization." (Mahbubani 1995, p. 107). If this is true, it stands in contrast to what has been documented by Putnam $(1995,1996)$ for the United States, where key indicators of social glue- he emphasizes associational memberships and survey measures of social trust- have fallen by about $10 \%$ each decade over the past thirty years. He regards social trust and associational membership - trust and engagement- as two key facets of social capital. The U.S. social survey shows a strong positive correlation across individuals between associational memberships and the extent to which individuals believe that people can be trusted. Both variables are also strongly positively correlated with education, with a marginal effect that increases with the level of education. This correlation with education increases the significance of the large aggregate reductions in trust and engagement, since average educational levels in the United States have grown substantially during the post-1960 decades, just as social capital has been declining.

If social glue is either stronger or longer-lasting in Asia than elsewhere, that might provide another hypothesis to consider as part of the explanation for sustained fast economic growth in Asia. Those devoted to the harder edges of the social sciences, economists among them, tend to resist the use of social and cultural variables as part of the explanation for economic differences. This may in part be due to insularity, but no doubt also reflects a resistance to variables that are difficult to measure, whose role in a causal structure may be only vaguely defined, and which themselves are difficult to explain. However, there is increasing scope for more organized quantitative measurement and evaluation of social structures and their differences over time and among countries. Inglehart (1994) and colleagues have developed a large scale international survey that covers some of the key variables emphasized by Putnam in his analysis of social capital 
in the United States. For thirty-five countries, in 1990-91, Inglehart has data (shown in Figure 14 of Putnam 1995) on both trust and associational memberships. The correlation between the two measures is high across countries $(r=.65)$, just as Putnam found across individuals in the United States.

Unfortunately for our present purposes, the Inglehart 33-country includes only three Asian economies (China, Korea, and Japan), and observations are not available for dates before 1990 . Thus lack of country coverage and absence of earlier observations foreclose the possibility of directly testing whether cross-country differences in the extent or durability of social capital help to explain growth differences among Asian economies or between the Asian economies and the rest of the world. Although the United States was subject to significant reductions in social capital between 1960 and 1990, the Inglehart data still show U.S. social capital in 1990 to be high relative to most other countries (and about equal to that in Canada, except that the level of trust is slightly higher in Canada, and the extent of associational memberships slightly higher in the United States), and generally higher than in the three Asian economies. China has a higher degree of trust (.60 compared to .50 for the United States, .52 for Canada, .42 for Japan and .34 for Korea), but all three Asian countries have lower associational memberships ${ }^{21}$ than in North America. Aside from the high level of trust in China, only the Nordic countries and the Netherlands have higher levels of social capital, by either of the two measures, than do Canada and the United States. It might be useful to attempt, for the thirty-five country sample, to see if some combination of the two measures helps to explain the residuals from more conventional cross-sectional growth equations. The risks of simultaneous bias will be considerable, as social capital, like the Mauro efficiency measure discussed earlier, is correlated with GDP per capita, and has not been observed except at the end of the period for which per capita GDP data are available. However, even with this bias working in its favour, associational membership has a negative rather than a positive correlation with $1950-88$ economic growth ( $r=-22$ in Inglehart 1994), so it is unlikely to become

\footnotetext{
${ }^{21}$ Associational memberships per capita in 1990 were 1.94 in the United States, 1.68 in Canada, 1.47 in South Korea, 83 in China and .49 in Japan.
} 
significantly positive in a more complete model of comparative growth. Inglehart finds, however, in partial support of Olson's (1982) view that long-established organizations tend to encourage wasteful rent-seeking, that the partial correlation between growth and associational membership is negative among the richer countries and positive among the poorer countries.

Inglehart (1994) has also tried to use the World Values survey data to supplement the social capital approach by asking if there are systematic differences in the values thought important to teach to children. His hypothesis is that growth prospects are likely to be brighter in societies where children are motivated to achieve. Three goals (thrift, determination, and hard work) are thought to favour growth, and three others (obedience, religious faith, and respect) to hold it back. The average of the first three minus the average of the second three is his index of achievement motivation. He finds a significant positive correlation across 43 countries between a simpler version of the index (thrift minus obedience) and economic growth over the 1950-88 period. Among the 43 countries, China and South Korea have the highest values of the index, with Japan sixth, Canada 28th, the United States 30th, and India 41 st. This index is less obviously subject to simultaneous feedback than are some of the measures of institutional structure. Both halves of the index reflect values that are culturally determined, but are probably not influenced by economic and policy variables, although actual savings behaviour, in contrast to attitudes towards thrift, is influenced by taxation and other policies. It is not clear exactly how parental attitudes about what should be taught to children would influence the prospects for growth, but the general line of the argument is clear. The data, being available only for one survey date, provide no guidance about how these opinions and attitudes change over time.

We do not have enough data to test the likely growth effects of either social capital or cultural values among the Asian countries, but it might nonetheless be worthwhile to see if the hypothesized relations hold among the industrial countries for which more complete data are available. Table 1 shows the results of regressions explaining the cumulative log differences 1962 - 
1989 in aggregate efficiency measures in seventeen OECD countries ${ }^{22}$. The independent variables include the 1962 logarithmic gap between each country's efficiency level and that in the United States, capturing convergence effects, and each of the measures described above for social capital and educational values. The primary measures are associational memberships, trust, thrift and obedience. The social capital measure is an equally weighted combination of trust and associations. None of the measures have the expected signs. In fact, the measures of social capital in 1990 are significantly negatively associated with productivity growth from 1962 to 1990 . Does this mean that the factors that may have induced faster growth have also tended to reduce trust and associational memberships? However, Putnam reports that measures of social capital tend to be more stable over time than among communities, so that it we might still expect to find levels of high social capital positively correlated with high growth if, as was found in Putnam (1993) and Helliwell and Putnam (1995) in the case of Italian regions, social capital is good for growth.

Perhaps the positive growth effects of social capital and thrift, the latter especially, flow through their effects on investment. If so, then the use of efficiency measures, which already remove the per capita growth effects of different investment rates (except to the extent that there are positive spillovers from investment to efficiency levels) would miss some or all of the positive growth effects. To check this possibility, tests were run to see if the international differences in the 1963-89 ratios of gross investment to GDP were positively influenced by any of the measures of social capital or values. They were not, and nor were measures of the average growth of GDP per capita.

The results in Table 1 are thus not consistent with the results of Putnam (1993) and Helliwell and Putnam (1995) for the regions of Italy, or with the results reported by Inglehart (1994) for his 35-country sample. The next step in unravelling the puzzle will probably require

${ }^{22}$ Except for the social capital and values variables, the data are the same as those developed and used in Helliwell (1994c). The efficiency measure is drawn from the application of a constant-returns Cobb-Douglas production function based on capital and employment. Using a Divisia index for the growth of measured factor inputs, rather than a Cobb-Douglas function, gives identical results, as described in Helliwell (1994c). 
social capital measures for a broader range of countries and regions, and with more variation over time. This may be possible for the states of the United States, but is not likely to be possible for the countries of Asia.

What can be concluded about the importance of social capital and cultural attitudes in explaining international differences in economic growth? It is simply too early to make any assessment, in my view, but I suspect that direct attempts to measure and explain various aspects of how society works will play an increasing role in comparative economics. Perhaps it may sometime be possible to make inferences about social as well as technological ideas that can usefully be imported from other societies.

In the meantime, the most parsimonious way of interpreting the growth experiences of the individual countries and groups of countries within Asia is that early openness seems to have encouraged early growth, raising the possibility that the increasing openness of the countries of South Asia will cement and accelerate their recent encouraging growth prospects. Exactly which channels, and which institutions, are most important to the successful transfer of productivity from the richer to the poorer countries remains, for now, an intriguing mystery. The role of international differences in social capital, and of changes in social capital from one generation to another remains another key question for research. The question is likely to be asked and answered first for the industrial countries, where there is a longer and more complete set of available data. On these issues, the Asian experiences remain, for now, inscrutable.

\section{REFERENCES}

Abramovitz, M. (1979) "Rapid Growth Potential and its Realization: The Experience of Capitalist Economies in the Postwar Period." In E. Malinvaud, ed., Economic Growth and Resources (London: Macmillan) 1-30.

Abramovitz, M. (1990) "The Catch-up Factor in Postwar Economic Growth." Economic Inquiry: 1-18.

Alesina, A and R. Perotti (1994) "The Political Economy of Growth: A Critical Survey of the Recent 
Literature." World Bank Economic Review 8: 351-71.

Backus, D.K., P.J. Kehoe and T.J. Kehoe (1991) "In Search of Scale Effects in Trade and Growth." Working Paper No. 451 (Minneapolis, Federal Reserve Bank).

Barro, R.J. (1991) "Economic Growth in a Cross Section of Countries." Quarterly Journal of Economics 106:407-44.

Baumol, W.J. (1986) "Productivity Growth, Convergence and Welfare: What the Long-Run Data Show." American Economic Review 76: 1072-85.

Baumol, W.J., and E.N. Wolff (1988) "Productivity Growth, Convergence and Welfare: Reply." American Economic Review 78: 1155-59.

Ben-David, Dan (1993) "Equalizing Exchange: Trade Liberalization and Income Convergence." Quarterly Journal of Economics 108: 653-80.

Ben-David, Dan (1994) "Income Disparity Among Countries and the Effect of Freer Trade." In L.L. Pasinetti and R.M. Solow, eds., Economic Growth and the Structure of Long-Term Development. (London: Macmillan) forthcoming.

Boskin, M.J. and L.J. Lau (1992) "Capital, Technology and Economic Growth." In N. Rosenberg, R. Landau and D. Mowery, eds., Technology and the Wealth of Nations (Stanford: Stanford University Press).

Brander, J.A. (1992) "Comparative Economic Growth: Evidence and Interpretation." Canadian Journal of Economics 25: 792-818.

Coe, D.T. and E. Helpman (1993) "International R\&D Spillovers." NBER Working Paper No. 4444. (Cambridge: National Bureau of Economic Research).

Dollar, D. (1992) "Outward-Oriented Developing Countries Really Do Grow More Rapidly: Evidence From 95 LDCs, 1976-1985." Economic Development and Cultural Change 52344.

Dowrick, S. and D-T. Nguyen (1989) "OECD Comparative Economic Growth 1950-85: Catch-Up and Convergence." American Economic Review 79: 1010-30.

Dowrick, S. and N. Gemmell (1991) "Industrialisation, Catching Up and Economic Growth: A Comparative Study Across the World's Capitalist Economies." Economic Journal 101:263275 .

Easterly, W. (1994) "Explaining Miracles: Growth Regressions Meet the Gang of Four." In T. Ito 
and A. Kreuger, eds., Lessons From East Asian Growth. Vol 4 of NBER-EASE conference series. (Chicago: University of Chicago Press)

Easterly, W., M. Kremer, L. Pritchett and L. Summers (1993) "Good Policy or Good Luck? Country Growth Performance and Temporary Shocks." NBER Working Paper No. 4474. (Cambridge: National Bureau of Economic Research).

Edwards, S. (1993) "Openness, Trade Liberalization, and Growth in Developing Countries." Journal of Economic Literature 31: 1358-93.

Fields, G.S. (1994) "Changing Labor Market Conditions and Economic Development in Hong Kong, the Republic of Korea, Singapore, and Taiwan, China." World Bank Economic Review 8: 395-414.

Fukuda, S. and H. Toya (1994) "Conditional Convergence in East Asian Countries: The Role of Exports in Economic Growth." In T. Ito and A. Kreuger, eds., Lessons From East Asian Growth. Vol 4 of NBER-EASE conference series. (Chicago: University of Chicago Press)

Grossman, G.M. and E. Helpman (1991) Innovation and Growth in the Global Economy. (Cambridge: MIT Press).

Harrison, A. and A. Revenga (1995) "The Effects of Trade Policy Reform: What Do We Really Know?" NBER Working Paper No. 5225. (Cambridge: National Bureau of Economic Research).

Helliwell, John F. (1994a) "International Growth Linkages: Evidence from Asia and the OECD." In T. Ito and A.O. Krueger, eds. Macroeconomic Linkage: Savings, Exchange Rates and Capital Flows (Chicago: University of Chicago Press) 7-28.

Helliwell, John F. (1994b) "Empirical Linkages Between Democracy and Economic Growth." British Journal of Political Science 24: 225-48.

Helliwell, John F. (1994c) "Trade and Technical Progress." In L.L. Pasinetti and R.M. Solow, eds., Economic Growth and the Structure of Long-Term Development. (London: Macmillan)

Helliwell, John F. (1995) "Asian Economic Growth" In W. Dobson and F. Flatters, eds. Pacific Trade and Investment: Options for the 90s. (Kingston: John Deutsch Institute).

Helliwell, John F., and Alan Chung (1991a) "Macroeconomic Convergence: International Transmission of Growth and Technical Progress." In P. Hooper and J.D. Richardson, eds., International Economic Transactions: Issues in Measurement and Empirical Research. (Chicago: University of Chicago Press) 388-436. 
Helliwell, John F. and Alan Chung (1991b) "Are Bigger Countries Better Off?" In R. Boadway, T. Courchene and D. Purvis, eds., Economic Dimensions of Constitutional Change (Kingston: John Deutsch Institute) 1991, 346-67.

Helliwell, John F. and Alan Chung (1993) "Tri-polar Growth and Real Exchange Rates: How Much Can be Explained by Convergence?" In L.R. Klein, ed., A Quest for a More Stable World Economic System (Boston: Kluwer) 151-205.

Helliwell, John F. and Alan Chung (1995) "Convergence and Growth Linkages Between North and South." In D. Currie and D. Vines, eds., Macroeconomic Linkages Between North and South (Cambridge: Cambridge University Press).

Helliwell, John F., and Robert D. Putnam (1995) "Social Capital and Economic Growth in Italy." Eastern Economic Journal 21(3):295-307.

Inglehart, R. (1994) "The Impact of Culture on Economic Development: Theory, Hypotheses and Some Empirical Tests." (Ann Arbor: University of Michigan)

International Monetary Fund (1995) World Economic Outlook May 1995. (Washington: International Monetary Fund).

Keefer, P. and S. Knack (1993) "Why Don't Poor Countries Catch Up? A Cross-Country Test of an Institutional Explanation." IRIS Working Paper No. 60. (College Park, Maryland: Center for Institutional Reform and the Informal Sector)

Lee, Jong-Wha (1993) "International Trade, Distortions, and Long-Run Economic Growth." IMF Staff Papers 40 (2): 299-329.

Lucas, R.E. (1988) "On the Mechanics of Economic Development." Journal of Monetary Economic 22: 3-32.

Lucas R.E. (1990) "Why Doesn't Capital Flow from Rich to Poor Countries?" American Economic Review 90 (2): 92-96.

Mahbubani, K. (1995) "The Pacific Way." Foreign Affairs (January/February 1995) 100-11.

Maddison, A. (1982) Phases of Capitalist Development. (Oxford: Oxford University Press).

Mankiw, G., D. Romer and D. Weil (1992) "A Contribution to the Empirics of Economic Growth." Quarterly Journal of Economics 107:407-37.

Mauro, P. (1995) "Corruption and Growth." Quarterty Journal of Economics 110:681-712. 
Olson, M. (1982) The Rise and Decline of Nations. (New Haven: Yale University Press).

Park, Y.C. (1991) "Export-Led Growth and Economic Liberalisation in South Korea." In P. Marer and S. Zecchini, eds., The Transition to a Market Economy. Vol I, 150-2. (Paris: OECD)

Putnam, Robert D. (1993) Making Democracy Work: Civic Traditions in Modern Italy. (Princeton: Princeton University Press).

Putnam, Robert D. (1996) "Bowling Alone: Democracy in America at the End of the Twentieth Century." forthcoming in A. Hadenius, ed. (New York: Cambridge University Press)

Putnam, Robert D. (1995) "Tuning in, Tuning out: The Strange Disappearance of Social Capital in America." (1995 Ithiel de Sola Pool Lecture to the American Political Science Association)

Rodrik, D. (1994) "King Kong Meets Godzilla: The World Bank and the East Asian Miracle" CEPR Discussion Paper No. 944. (London: Centre for Economic Policy Research).

Romer, P.M. (1986) "Increasing Returns and Long-Run Growth." Journal of Political Economy 94: 1002-37.

Ruffin, R. J. (1993) "The Role of Foreign Investment in the Economic growth of the Asian and Pacific Region." Asian Development Review 11(1): 1-23.

Sachs, J.D. and A. Warner (1995) "Economic Reform and the Process of Global Integration." Brookings Papers on Economic Activity 1:1995: 1-118.

Solow, R.M. (1956) "A Contribution to the Theory of Economic Growth." Quarterly Journal of Economics 70: 65-94.

Solow, R.M. (1957) "Technical Change and the Aggregate Production Function." Review of Economics and Statistics 39: 312-20.

Summers, R. and A. Heston (1991) "The Penn World Table (Mark 5): An Expanded Set of International Comparisons, 1950-1988." Quarterty Journal of Economies 106: 327-68.

World Bank (1993) The East Asian Miracle: Economic Growth and Public Policy. (Washington: World Bank).

Young, Alwyn (1992) "A Tale of Two Cities: Factor Accumulation and Technical Change in Hong Kong and Singapore." NBER Macroeconomics Annual 1992.

Young, Alwyn (1995) "The Tyranny of Numbers: Confronting the Statistical Realities of the East Asian Growth Experience." Quarterly Journal of Economics 110: 641-680. 
Table 1

Effects of Social Capital and Values on Productivity Growth in OECD Countries

\begin{tabular}{|c|c|c|c|c|c|}
\hline Equation & (i) & (ii) & (iii) & (iv) & (v) \\
\hline \multicolumn{6}{|l|}{ No. of } \\
\hline Observations & 17 & 17 & 17 & 17 & 17 \\
\hline Estimation Method & OLS & OLS & OLS & OLS & OLS \\
\hline Dependent Variable & $\begin{array}{l}\text { dlneff } \\
1962-89\end{array}$ & $\begin{array}{l}\text { dlneff } \\
1962-89\end{array}$ & $\begin{array}{l}\text { dlneff } \\
1962-89\end{array}$ & $\begin{array}{l}\text { dlneff } \\
1962-89\end{array}$ & $\begin{array}{l}\text { dlneff } \\
1962-89\end{array}$ \\
\hline Constant & $\begin{array}{l}.447 \\
(3.6)\end{array}$ & $\begin{array}{l}.384 \\
(3.2)\end{array}$ & $\begin{array}{l}.441 \\
(3.5)\end{array}$ & $\begin{array}{l}.180 \\
(1.5)\end{array}$ & $\begin{array}{l}.004 \\
(0.0)\end{array}$ \\
\hline $\begin{array}{l}\text { Coefficients: } \\
\text { gap63 }\end{array}$ & $\begin{array}{l}.563 \\
(6.0)\end{array}$ & $\begin{array}{l}.514 \\
(6.6)\end{array}$ & $\begin{array}{l}.545 \\
(6.9)\end{array}$ & $\begin{array}{l}.594 \\
(6.3)\end{array}$ & $\begin{array}{l}.607 \\
(6.9)\end{array}$ \\
\hline
\end{tabular}

trust $\quad-.59$

(2.7)

associations

(2.3)

social capital

(2.7)

thrift

-.23
$(2.7)$

obedience

$-.08$

(0.3)

$\begin{array}{lccccc}\overline{\mathbf{R}^{2}} & .807 & .787 & .806 & .705 & .745 \\ \text { S.E.E. } & .105 & .111 & .106 & .131 & .121\end{array}$

Notes: Absolute values of $t$ statistics are in parentheses. The dependent variable is the logarithn of total the ratio of the 1989 to the 1962 efficiency level in each country, using the same data as in Helliwell (1994c), with Australia and New Zealand removed from the sample because they were not the World Values sample. Thrift, trust, and obedience are all measured as proportions of repondents, while associations is the average number of associations to which respondents belong. All four variables are from the World Values Survey database from the University of Michigan. 
Fig 1 GDP growth in Developing Regions

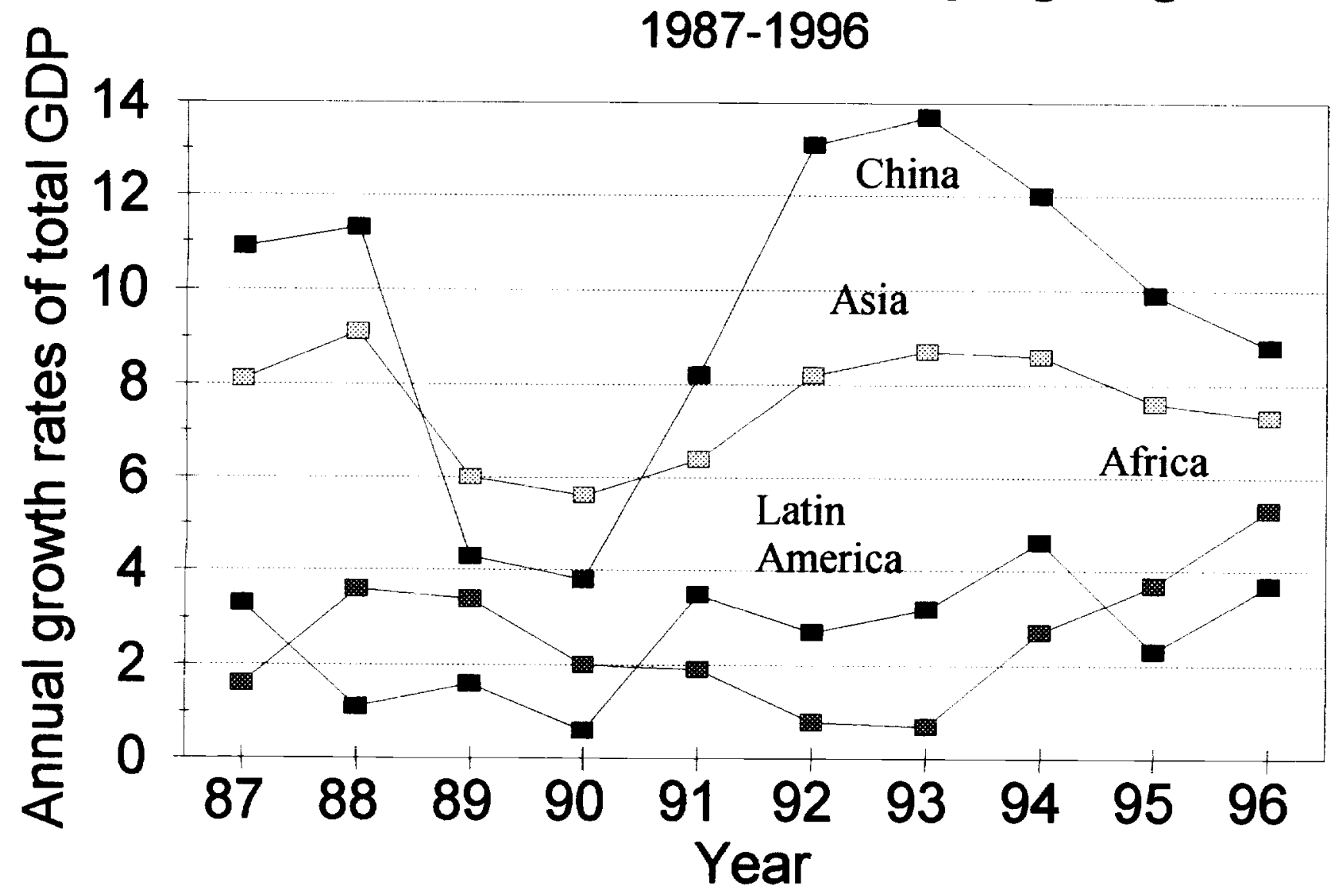




\section{Fig 2 Shares of Global Totals}

1994 Exports, GDP, and Population

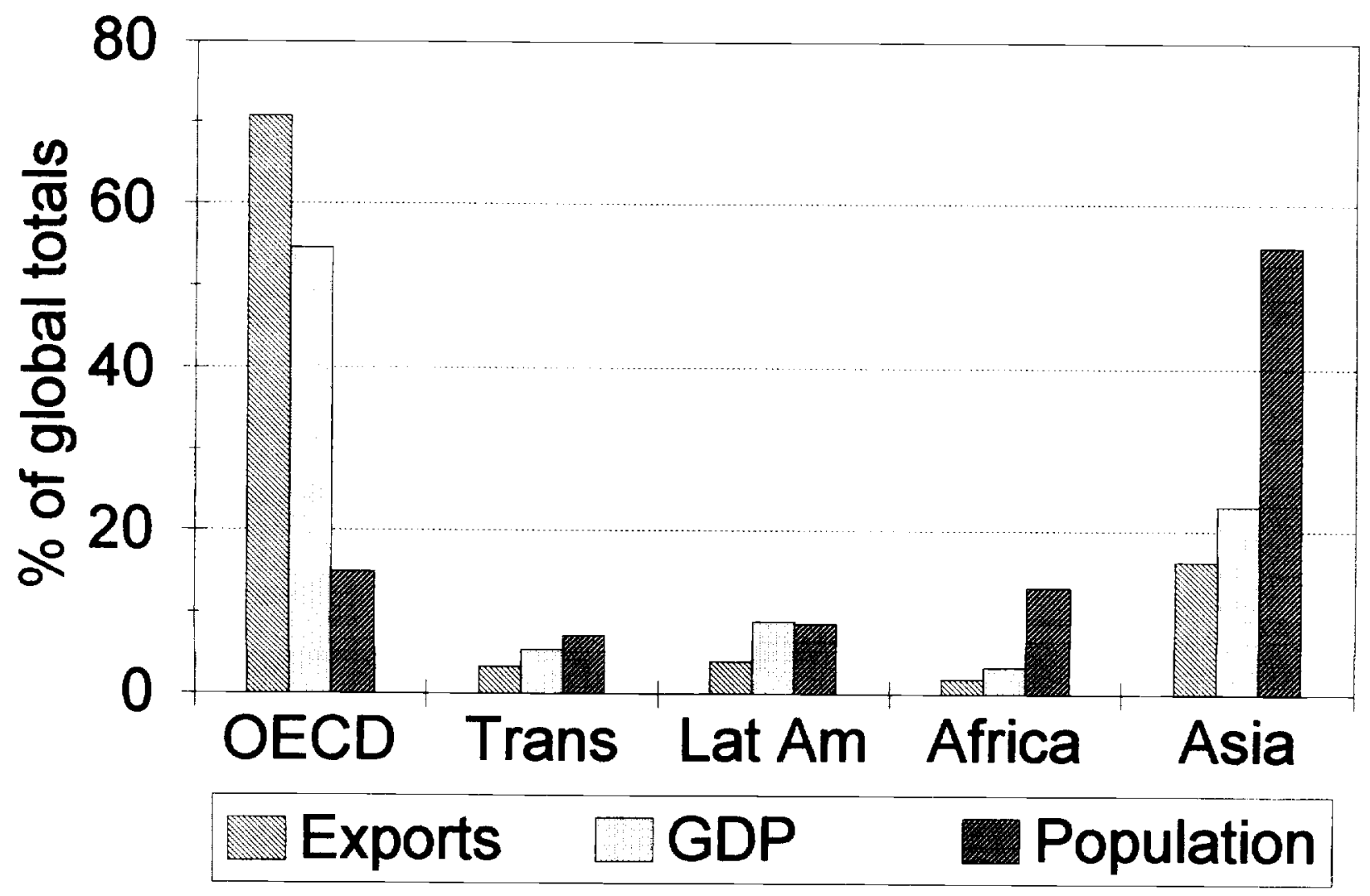




\section{Fig 3 Asian Growth in the 1980s vs per capita income in 1980}

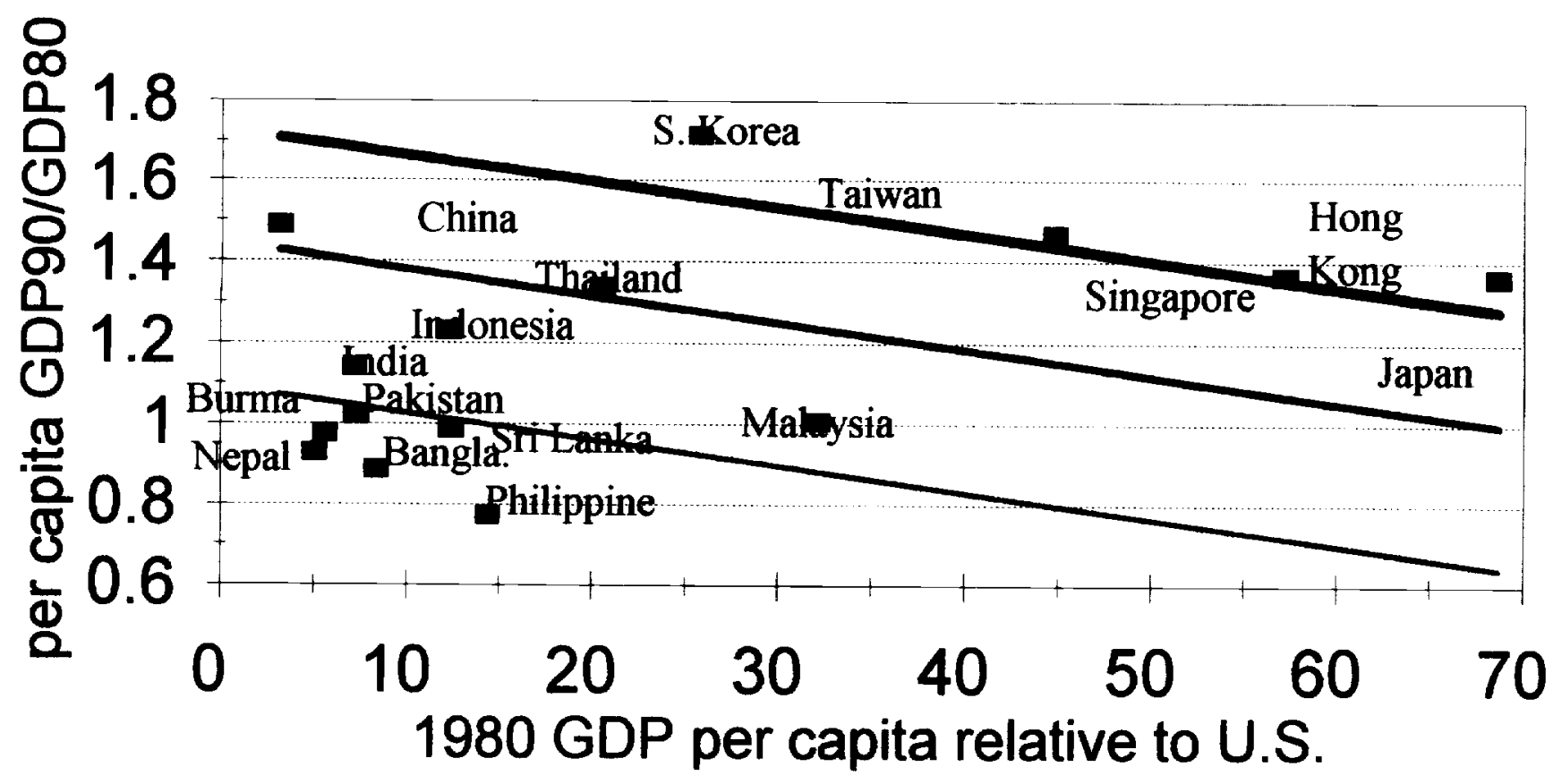

- Low tariffs - Medium tariffs - High tariffs 
Fig 4a GDP growth in Japan + 4 Tigers

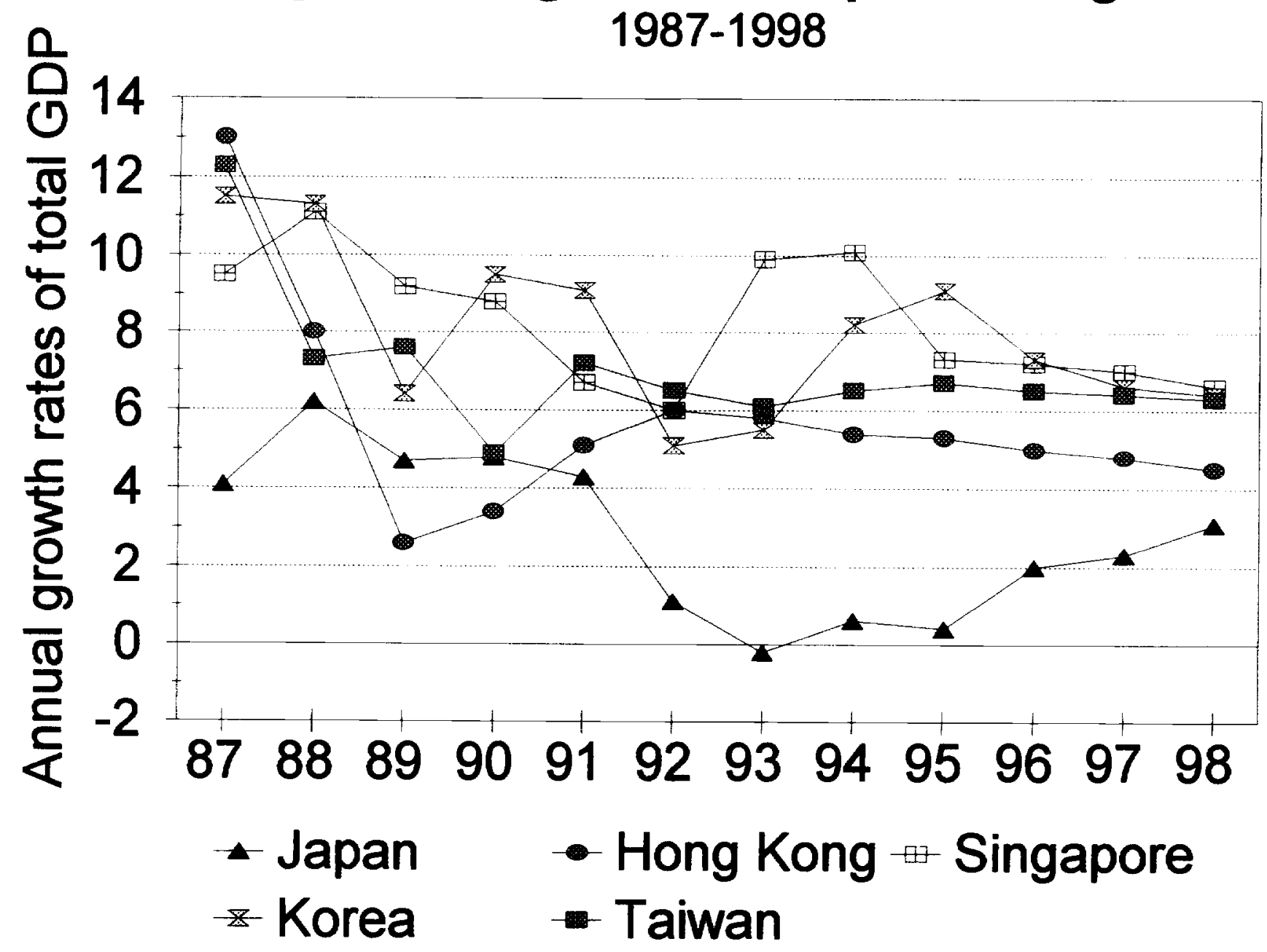


Fig 4b Growth in China + other E. Asia

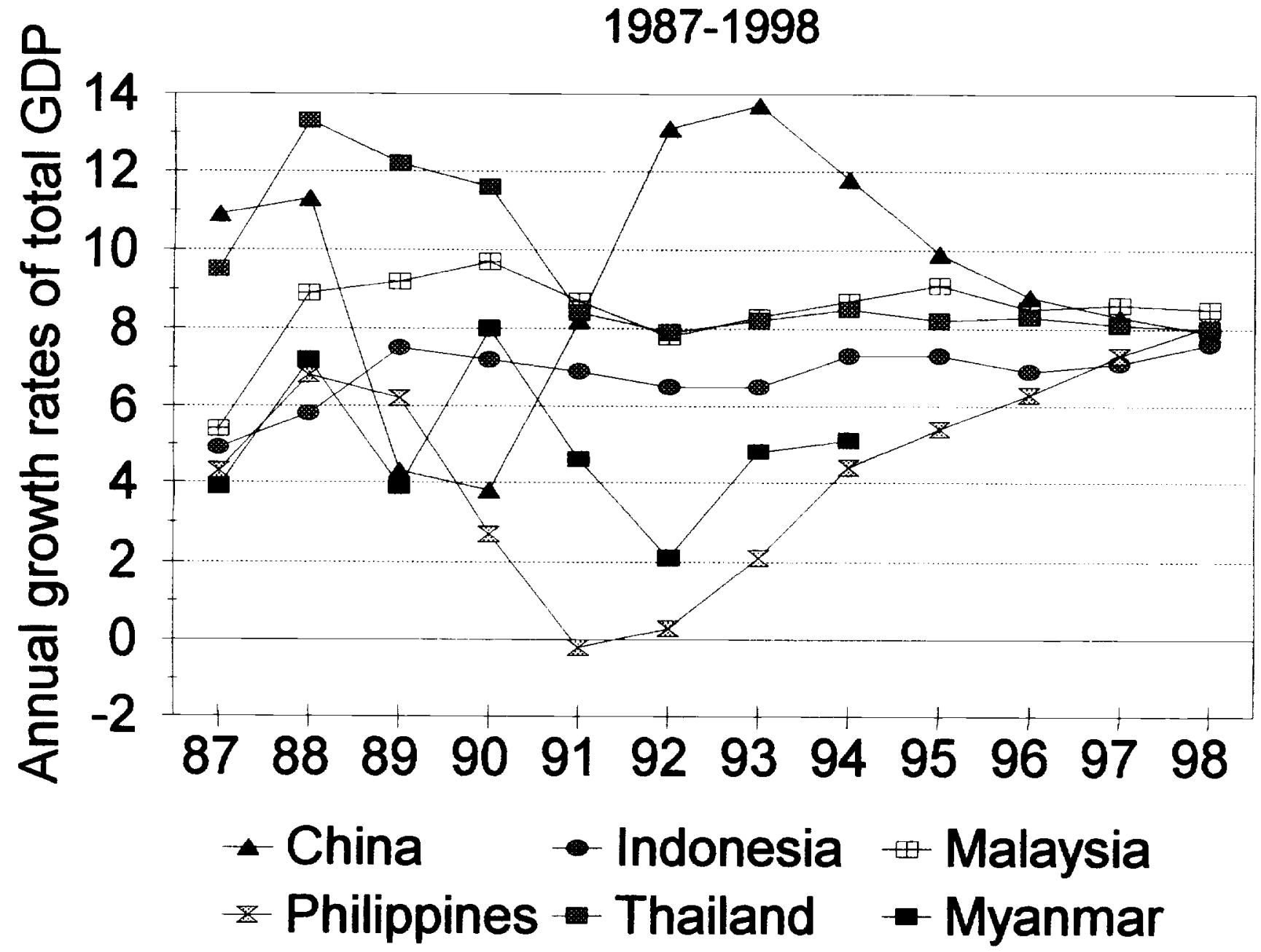


Fig 4c GDP Growth in South Asia

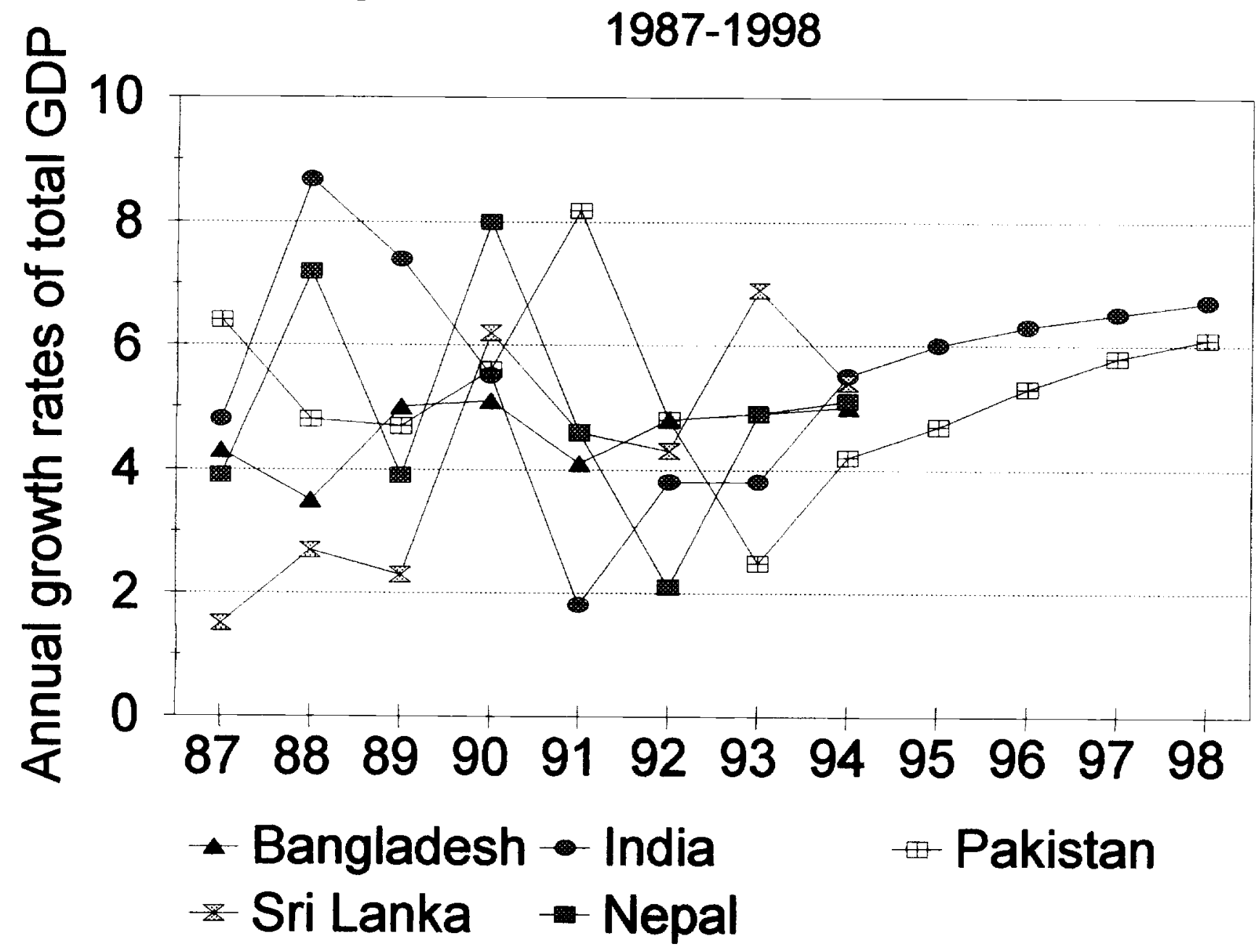


Fig 5 Growth in Asian Regions

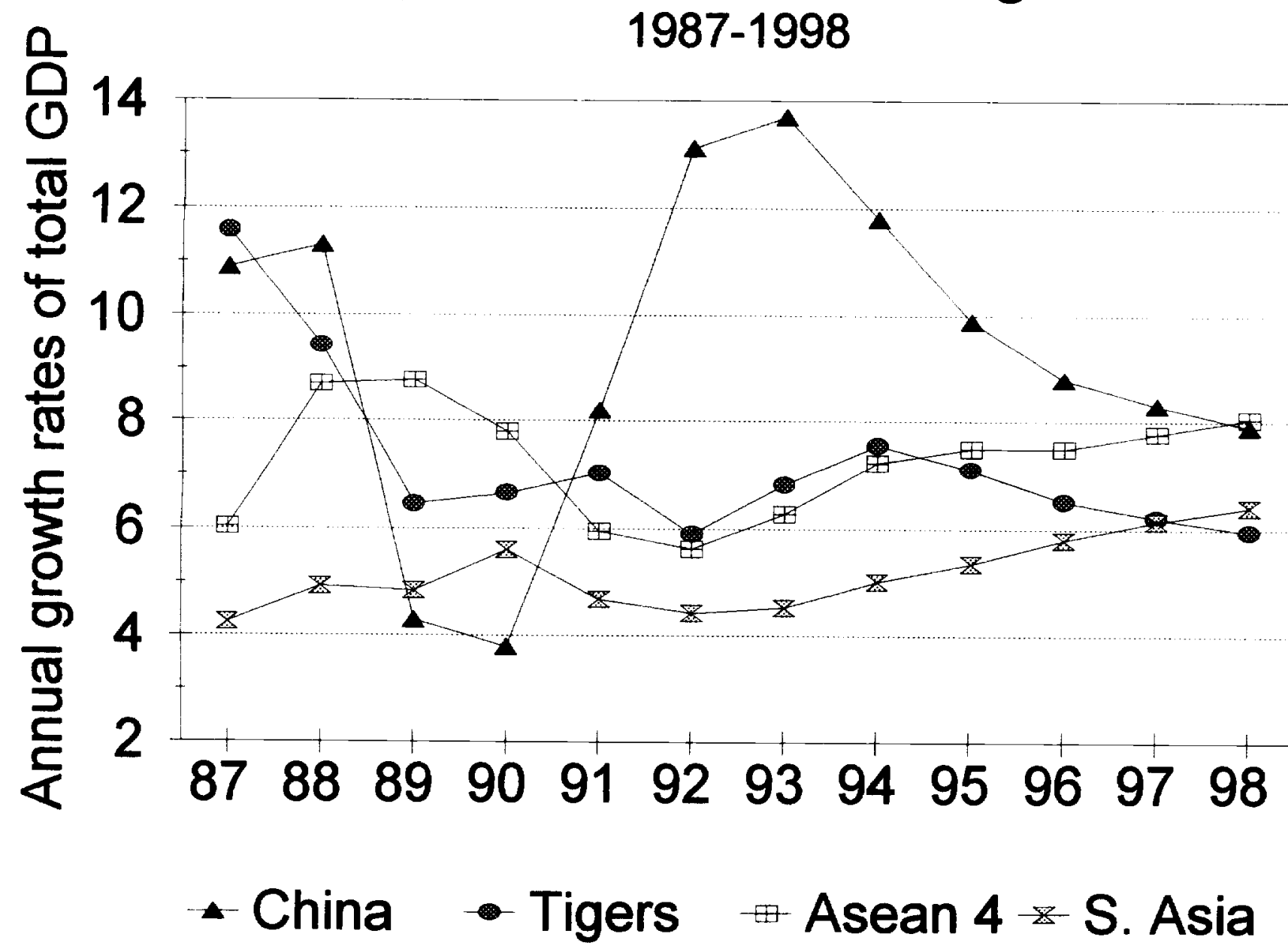




\section{Fig 6 Income and Govt Efficiency 1980 GDP/capita vs Mauro's Index}

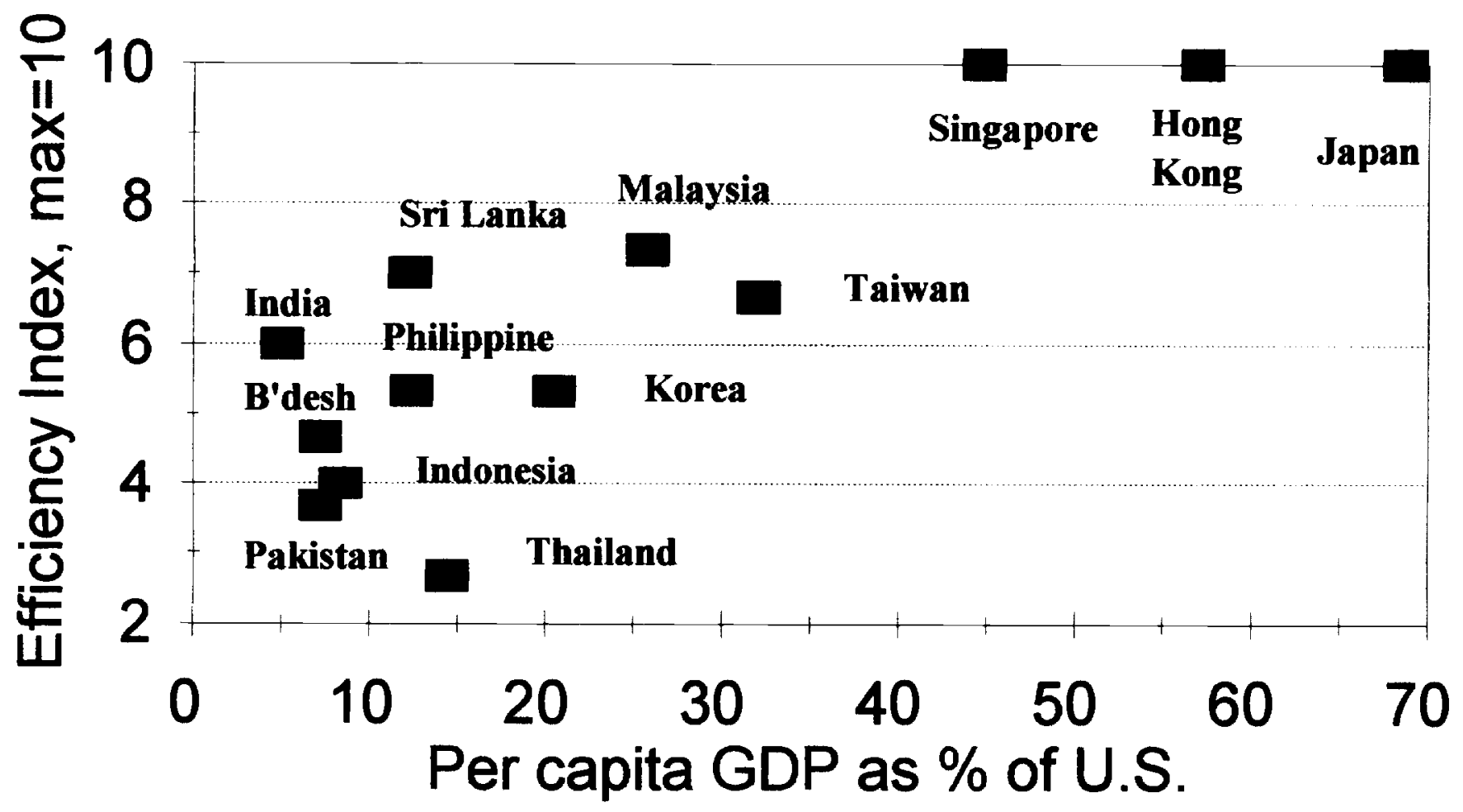

